Original Research Article

\title{
Adverse drug reactions reporting among nursing staff and students: a validated questionnaire based knowledge, attitude and practice study
}

\author{
Lohit K. $^{1 *}$, Leena A. ${ }^{2}$, Maria Jose ${ }^{3}$, Amruta A. Pandit ${ }^{4}$
}

\begin{abstract}
${ }^{1}$ Department of Pharmacology, Sri Siddhartha Medical College, Tumakuru, Karnataka, India ${ }^{2}$ Department of Pharmacology, PES Institute of Medical Sciences and Research, Kuppam, Andhra Pradesh, India ${ }^{3}$ Department of Pharmacology, Jubilee Mission Medical College and Research Institute, Thrissur, Kerala, India

${ }^{4}$ Department of Pharmacology, St John's National Institute of Health Sciences, Bengaluru, Karnataka, India
\end{abstract}

Received: 29 December 2016 Accepted: 01 February 2017

*Correspondence to:

Dr. Lohit K.,

Email: lohitk4u@gmail.com

Copyright: (C) the author(s), publisher and licensee Medip Academy. This is an openaccess article distributed under the terms of the Creative Commons Attribution NonCommercial License, which permits unrestricted noncommercial use, distribution, and reproduction in any medium, provided the original work is properly cited.

\begin{abstract}
Background: Lack of knowledge regarding pharmacovigilance and adverse drug reaction (ADR) reporting among healthcare providers have been identified as major factors for under reporting of ADR in developing countries. Hence this study was planned to assess the knowledge and attitude of nursing faculty and students towards ADR reporting and also to determine the barriers to reporting ADR.

Methods: A validated questionnaire based cross sectional study conducted among the nursing faculty and students in a tertiary health care center. Data was assessed by frequency, percentage, mean and standard deviation. Statistical analysis was performed by using SPSS version 22 .

Results: The composite score on knowledge on ADR reporting was found to be moderate among nursing staff, GNM and BSc nursing students. The knowledge on burden due to ADR was found to be poor among all the three categories. Around $70 \%$ of all the respondents were of the opinion that ADR reporting by one person can make a significant difference to the community. More than $80 \%$ of nursing staff and GNM students opined one should have a suspicion of possible ADR during treatment. Majority of the nursing staff were in favour of mandatory and voluntary ADR reporting in the hospital.

Conclusions: The nurses were only moderately aware of pharmacovigilance and adverse drug reaction reporting. Though the attitude towards ADR reporting was adequate, our study has shown that the actual practice of ADR reporting is unsatisfactory. Hence, it is essential to include pharmacovigilance training in the undergraduate teaching programs of nurses to promote reporting of adverse reactions.
\end{abstract}

Keywords: Adverse drug reaction, Attitude, India Knowledge, Nurse, Practice

\section{INTRODUCTION}

Adverse drug reactions (ADRs) are an important public health problem in terms of mortality, morbidity as well as costs. Spontaneous reporting of ADRs by health care professionals (HCP) plays a major role in establishing the frequency of occurrence of known ADRs, detection of new, serious and even unknown reactions. This helps in signal detection and enables regulatory agencies to formulate drug use guidelines, issue warnings or even ban/withdraw the drug from the market. A constant effort has been put by the concerned authorities in reinforcing reporting practices. However studies worldwide have shown gross under reporting with a median rate of around 
94\%. ${ }^{1}$ Knowledge and attitude of health care professionals about ADR greatly influences the extent of reporting. Identifying the factors affecting reporting is thus vital to implement interventions to enhance the rate and quality of reporting.

Nurses are an integral part of the health care and delivery system. They are known to have an important role in ADR reporting in hospitals. ${ }^{2}$ Thus, their level of awareness regarding ADRs, beliefs, opinions and attitudes towards reporting, the difficulties of spontaneous reporting of ADRs that they face will have an impact on the rate of reporting. Hence this study was conducted to assess the knowledge, attitude and practice patterns of nursing faculty and students towards ADR reporting and also to determine the barriers for reporting ADR.

\section{METHODS}

We conducted a questionnaire based cross sectional study at Sri Siddhartha Educational Institution, Tumakuru from August 2015 to March 2016. The study was approved by the institutional ethics committee with reference number SSMC/Pri/ethic/2185/2014. All the nursing faculty and students working in the institution were included except those unwilling to participate.

\section{Study tool}

A validated questionnaire was used to assess knowledge, attitude, practice and barriers to ADR reporting. ${ }^{3}$ The development of the questionnaire was conducted in a standardized manner, using an accepted measure development methodology which included item development, content and face validation, pilot testing, and test-retest validation. The internal consistency (reliability) of questionnaire was assessed by Cronbach's alpha coefficient, Cohen's kappa coefficients to assess reproducibility of knowledge questions and Paired T test to assess reproducibility of attitude questions. The questionnaire (appendix 1) was designed to assess the demographic details (age, sex, speciality and designation), their knowledge, attitudes and practice pattern towards pharmacovigilance. There were 25 questions in all (14 related to knowledge, 7 related to attitude and 4 to assess practice). The knowledge questions evaluated knowledge of burden due to ADR, reporting ADRs and pharmacovigilance. The attitude questions included opinions about reporting an ADR and includes the agreement towards preformed scale consisting agree, disagree and don't know. The practice questions were intended to collect the information regarding the approach to ADR or adverse event in their clinical experience. For categorization of knowledge, composite score was derived and divided into three groups. Score more than $66 \%$ is considered as adequate knowledge, 34 to $66 \%$ and less than $34 \%$ is considered as moderate and poor knowledge respectively.

\section{Statistical analysis}

We used descriptive statistics to summarize demographic data and to assess the response among nurses to identify knowledge, attitude of ADR reporting. Categorical variables were compared using Chi square test. Collected data was assessed by frequency, percentage, mean and standard deviation. A $\mathrm{p}$ value $<0.05$ was considered significant for all tests. Statistical analyses were performed using Statistical Package for the Social Sciences version 22.0 software (SPSS Inc, Chicago, IL, USA).

\section{RESULTS}

\section{Assessment of Knowledge on ADR reporting and ADR burden}

A total of 99 Nurses participated in the study. The overall level of knowledge on ADR reporting and ADR burden are summarized in Table 1. The composite score on knowledge of ADR reporting was found to be moderate among nursing staff, GNM and B.Sc. nursing students. The composite score on knowledge of burden due to ADR was found to be poor among all the three categories. Appendix attached.

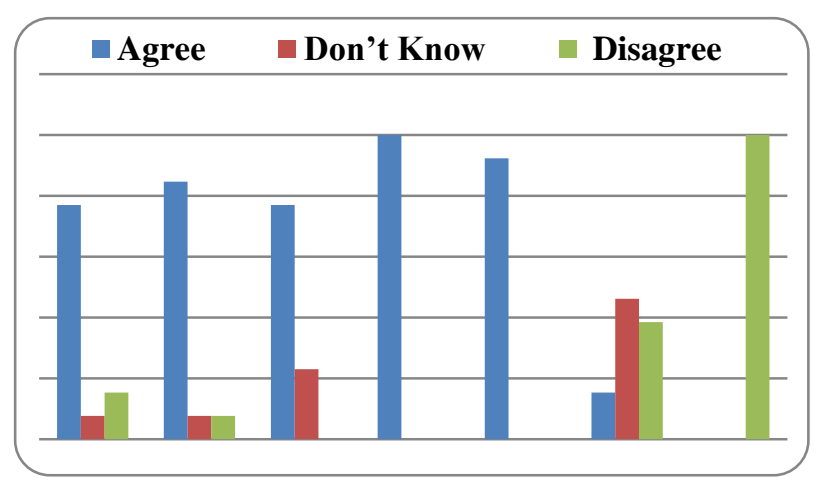

Figure 1: Response to the attitude questions from nursing staff $(\mathrm{N}=13)$.

Table 1: Overall level and composite score of knowledge on ADR reporting and ADR burden (N=99).

\begin{tabular}{|lllll|} 
& $\begin{array}{l}\text { Knowledge of ADR } \\
\text { reporting } \\
\text { Mean score (Max. 21) }\end{array}$ & $\begin{array}{l}\text { Knowledge of ADR } \\
\text { burden } \\
\text { Mean score (Max. 7) }\end{array}$ & $\begin{array}{l}\text { Composite score } \\
\text { Knowledge of ADR } \\
\text { Reporting (\%) }\end{array}$ & $\begin{array}{l}\text { Composite score } \\
\text { Knowledge of Burden } \\
\text { due to ADR (\%) }\end{array}$ \\
\hline Nursing Staff (13) & 9.46 & 2.51 & 45.05 & 30.77 \\
\hline GNM (31) & 9.81 & 0.87 & 46.7 & 12.44 \\
\hline B.Sc. (55) & 7.97 & 0.45 & 37.97 & 6.49 \\
\hline
\end{tabular}


Table 2: Attitude responses regarding adverse drug reaction reporting.

\begin{tabular}{|c|c|c|c|c|c|}
\hline & & & Number of respon & & \\
\hline No. & Attitude questions & Responses & Nursing staff (13) & GNM students (31) & B.Sc. Students (55) \\
\hline & One should be certain of & Agree & 10 & 14 & 22 \\
\hline A1: & the ADR due to particular & Don't know & 1 & 5 & 18 \\
\hline & drug & Disagree & 2 & 12 & 10 \\
\hline & One should have a & Agree & 11 & 27 & 30 \\
\hline A2: & suspicion of possible ADR & Don't know & 1 & 3 & 17 \\
\hline & during treatment & Disagree & 1 & 1 & 3 \\
\hline & ADR reporting by one & Agree & 10 & 24 & 41 \\
\hline A3: & person can make a & Don't know & 3 & 6 & 6 \\
\hline & the community & Disagree & 0 & 1 & 3 \\
\hline & ADR reporting in the & Agree & 13 & 27 & 39 \\
\hline A4: & hospital by health care & Don't know & 0 & 1 & 5 \\
\hline & $\begin{array}{l}\text { voluntary } \\
\text { voluta be }\end{array}$ & Disagree & 0 & 3 & 6 \\
\hline & ADR reporting in the & Agree & 12 & 12 & 24 \\
\hline A5: & hospital should be & Don't know & 1 & 14 & 18 \\
\hline & mandatory & Disagree & 0 & 5 & 8 \\
\hline & ADR reporting in the & Agree & 2 & 3 & 4 \\
\hline A6: & hospital should be & Don't know & 6 & 10 & 15 \\
\hline & financially rewarded & Disagree & 5 & 18 & 31 \\
\hline & & Agree & 0 & 3 & 5 \\
\hline A7: & ADosnital is not reguired & Don't know & 0 & 1 & 2 \\
\hline & & Disagree & 13 & 27 & 43 \\
\hline
\end{tabular}

Right responses are highlighted in bold font style.

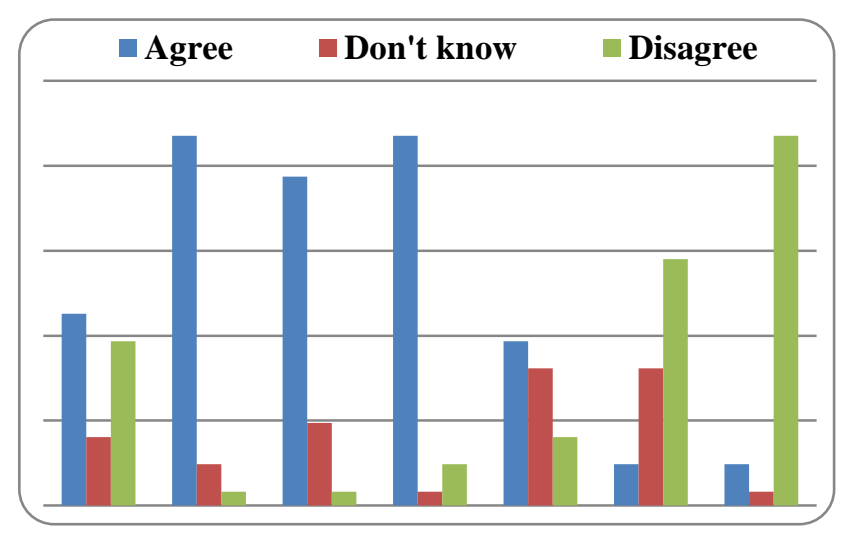

Figure 2: Response to the attitude questions from GNM Students $(\mathbf{N}=31)$.

\section{Assessment of attitude and practice on ADR reporting}

There were 7 questions to assess the attitude towards reporting of ADRs as summarized in Table 2. About 70\% of all the respondents were of the opinion that ADR reporting by one person can make a significant difference to the community. More than $80 \%$ of nursing staff and GNM students opined one should have a suspicion of possible ADR during treatment. Majority of the nursing staff were in favor of mandatory and voluntary ADR reporting in the hospital. Around $60 \%$ of the respondents disagreed on financial rewarding for ADR reporting. About $10-20 \%$ of GNM students and BSc students reported that $\mathrm{ADR}$ reporting in the hospital is not required (Figure 1, Figure 2 and Figure 3).

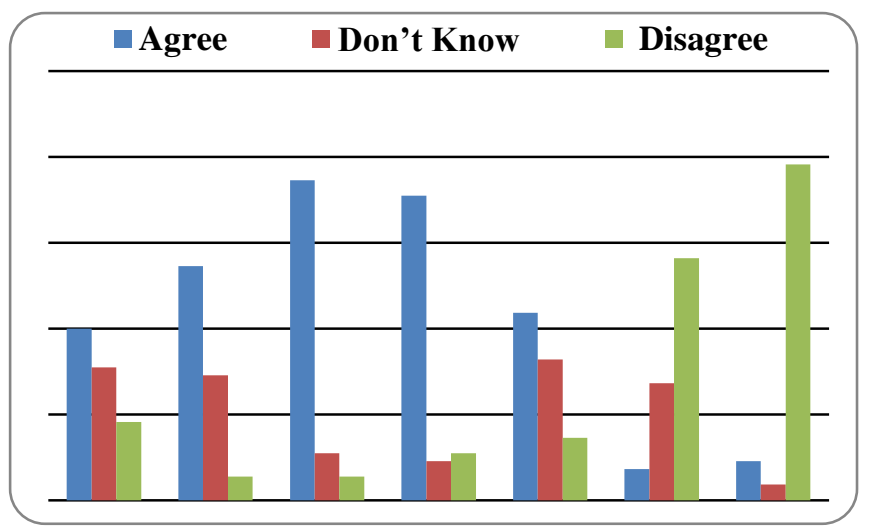

Figure 3: Response to the attitude questions from B.Sc. students $(\mathrm{N}=55)$.

\section{Barriers}

Responders declared that they were unaware of the system of pharmacovigilance, where to find the reporting form, how to fill it in and to whom and how to send the 
reporting form. None of the respondents had reported an ADR during their entire professional practice.

\section{DISCUSSION}

Under-reporting of ADRs is a universal phenomenon, which exists as an inherent weakness of current voluntary reporting schemes. ${ }^{4}$ Hospital nurses play an important role in ADR reporting. Given their unique position in patient care, the nurses are well placed to administer drugs as well as monitor the patient's response. They are often the first to be informed regarding any adverse reaction by the patient themselves or the caretakers. They are thus an important source for identifying, recording and also alerting the responsible physician about possible ADRs. Therefore it is logical and essential to involve nurses and encourage them to contribute to the ADR reporting system. ${ }^{2,5}$ Our study has found moderate knowledge regarding ADR reporting, poor knowledge of ADR burden and poor practice. The average knowledge score of the respondents was $43 \%$ on ADR reporting and $16.5 \%$ on ADR burden, indicating that there is still much to be done to educate the nurses regarding ADR reporting. In contrast, Indian studies at Mumbai, Mysore, and Muzzafarnagar have shown high knowledge, but poor practice for ADR, among prescribers which included nurses. ${ }^{6-8}$

The results of the present study showed that most of the staff nurses and nursing students had positive perception towards ADR reporting. The attitude level towards ADR reporting becoming mandatory and voluntary was the highest. All were of the opinion ADR reporting can bring significant difference to the community. Previous studies have also identified ADR reporting as a professional obligation. $^{4,9-11}$ ADR reporting as a professional obligation will have moral binding to healthcare professionals and ethical issues. The fact that over $20 \%$ of our GNM students and BSc nursing students believed that $\mathrm{ADR}$ reporting is not required in the hospital clearly shows the need for appropriate education regarding this issue that will probably make a significant difference in the number of our reports.

Actual practice of ADR reporting was unsatisfactory. The nurses in our study had never reported an ADR similar to results of studies by S Hanafi et al. ${ }^{9}$ and Backstrom et al unlike another study in which $25.6 \%$ of respondents (hospital pharmacists) had submitted Yellow Cards. ${ }^{12,13}$ Lack of training on how to report ADRs could be the probable reason for under reporting, similar to the low percentage of training imparted to healthcare professionals in previously reported studies from Indore and Trivandrum. ${ }^{14,15}$ Educational interventions such as CMEs, conference lectures on pharmacovigilance for students, training workshops on ADR have been found to improve the rate of reporting. ${ }^{16}$ Thus identifying the factors affecting reporting is vital so as to enable the pharmacovigilance teams to implement educational interventions to enhance the rate and quality of reporting of ADRs.

\section{CONCLUSION}

In conclusion, the present study has shown that though the level of knowledge about ADR reporting and attitude towards it was adequate, yet nurses showed poor practice of ADR reporting. Therefore, there is a need to increase the awareness regarding the importance of ADR reporting through various educational interventions, training the nurses on how to report an ADR and also including pharmacovigilance awareness programmes for GNM and BSc nursing students. All these steps would further help the nurses to contribute to pharmacovigilance efficiently.

\section{Funding: No funding sources}

Conflict of interest: None declared

Ethical approval: The study was approved by the Institutional Ethics Committee

\section{REFERENCES}

1. Hazell L, Shakir SA. Under-reporting of adverse drug reactions: a systematic review. Drug Saf. 2006;29(5):385-96

2. Hall M, McCormack P, Arthurs N, Feely J. The spontaneous reporting of adverse drug reactions by nurses. Br J Clin Pharmacol. 1995;40(2):173-5.

3. Lohit K, Vidya KR, Manjunath GN. Development and Validation of Questionnaire to Assess the Knowledge, Attitude and Practice towards Adverse Drug Reactions Reporting among Healthcare Professionals. Journal of International Medicine and Dentistry. 2016;3(2):63-72.

4. Kharkar M, Bowalekar S. Knowledge, attitude and perception/practices (KAP) of medical practitioners in India towards adverse drug reaction (ADR) reporting. Perspect Clin Res. 2012;3:90-4.

5. Backstrom M, Ekman E, Mjorndal T. Adverse drug reaction reporting by nurses in Sweden. Eur $\mathrm{J}$ Clin Pharmacol. 2007;63(6):613-8.

6. Gupta P, Udupa A. Adverse drug reaction reporting and pharmacovigilance: Knowledge, attitudes and perceptions among resident doctors. J Pharm Sci Res. 2011;3:1064-9.

7. Ramesh M, Parthasarathi G. Adverse drug reactions reporting: attitudes and perceptions of medical practitioners. Asian J Pharm Clin Res. 2009;2:10-4.

8. Ghosh S, Ali S, Chhabra L, Prasad C, Gupta A. Investigation of attitudes and perception of medical practitioners on adverse drug reaction reporting: a pilot study. T Ph Res. 2010;3:1-9.

9. Hanafi S, Torkamandi H, Hayatshahi A, Gholami K, Javadi M. Knowledge, attitudes and practice of nurse regarding adverse drug reaction reporting. Iran J Nurs Midwifery Res. 2012 Jan;17(1):21-5.

10. Sencan N, Altinkaynak M, Ferah I, Ozyildirim A, Ceylan EM, Clark PM. The knowledge and attitudes 
of physicians and nurses toward adverse event reporting and the effect of pharmacovigilance training: A hospital experience. Hacettepe University J Faculty Pharm. 2010;30(1):25-40.

11. Sivadasan S, Sellappan M. A study on the awareness and attitude towards pharmacovigilance and adverse drug reaction reporting among nursing students in a private university, Malaysia. Int J Curr Pharm Res. 2014;7(1):84-9.

12. Backstrom M, Mjorndal T, Dahlqvist R. Spontaneous reporting of adverse drug reactions by nurses. Pharmacoepidemiol Drug Saf. 2002;11(8):647-50.

13. Green CF, Mottram DR, Rowe PH, Pirmohamed M. Attitudes and knowledge of hospital pharmacists to adverse drug reaction reporting. Br J Clin Pharmacol. 2001;51(1):81-6.

14. Khan SA, Goyal C, Chandel N, Rafi M. Knowledge, attitude and practice of doctors to adverse drug reaction reporting in a teaching hospital in India: An observational study. J Nat Sci Biol Med. 2013;4:1916.

15. Remesh A. Identifying the reasons for under reporting of ADR: A cross sectional survey. Res J Pharm Biol Chem Sci. 2012;3:1379-86.

16. Hanafi S, Torkamandi H, Hayatshahi A, Gholami K, Shahmirzadi NA, Javadi MR. An educational intervention to improve nurses' knowledge, attitude, and practice toward reporting of adverse drug reactions. Iranian $\mathrm{J}$ of $\mathrm{N}$ and Mid Res. 2014;19(1):101-6.

Cite this article as: Lohit $\mathrm{K}$, Leena A, Jose M, Pandit AA. Adverse drug reactions reporting among nursing staff and students: a validated questionnaire based knowledge, attitude and practice study. Int J Basic Clin Pharmacol 2017;6:523-7. 